\title{
Cadherin-8 Is Required for the First Relay Synapses to Receive Functional Inputs from Primary Sensory Afferents for Cold Sensation
}

\author{
Sachihiro C. Suzuki, ${ }^{1 \star}$ Hidemasa Furue, ${ }^{2 *}$ Kohei Koga, ${ }^{2}$ Nan Jiang, ${ }^{2}$ Mitsuo Nohmi, ${ }^{3}$ Yuka Shimazaki, ${ }^{3}$ \\ Yuko Katoh-Fukui, ${ }^{4}$ Minesuke Yokoyama, ${ }^{5}$ Megumu Yoshimura, ${ }^{2}$ and Masatoshi Takeichi ${ }^{1}$ \\ ${ }^{1}$ RIKEN Center for Developmental Biology, Chuo-ku, Kobe 650-0047, Japan, ${ }^{2}$ Department of Integrative Physiology, Graduate School of Medical Sciences, \\ Kyushu University, Higashi-ku, Fukuoka 812-8582, Japan, ${ }^{3}$ Analytical Research Center for Experimental Sciences, Saga University, Nabeshima, Saga 849- \\ 8501, Japan, ${ }^{4}$ Division for Sex Differentiation, National Institute for Basic Biology Myodaiji, Okazaki 444-8787, Japan, and ${ }^{5}$ Brain Research Institute, Niigata \\ University, Niigata 951-8585, Japan
}

Classic cadherins, comprising multiple subtypes, mediate selective cell-cell adhesion based on their subtype-specific binding nature. Each subtype in the brain is expressed by restricted groups of functionally connected nuclei and laminas. However, whether each subtype has any specific role in neural circuitry remains largely unknown. Here, we show that cadherin-8 (cad8), a type-II classic cadherin, is important for cold sensation, whose circuitry is established by projection of sensory neurons into the spinal cord. Cad8 was expressed by a subset of neurons in the dorsal horn (DH) of the spinal cord, as well as by a small number of neurons in the dorsal root ganglia (DRGs), and the majority of cad8-positive DRG neurons coexpressed cold temperature/menthol receptor (TRPM8). We generated cad8 knock-out mice and analyzed lacZ markers expressed by the targeted cad8 locus using heterozygous mice. LacZ/cad8-expressing sensory neurons and DH neurons were connected together, and cad8 protein was localized around the synaptic junctions formed between them. This relation was, however, not disrupted in cad8-1- mice. We performed whole-cell patch-clamp recordings from DH neurons in spinal cord slices, in combination with menthol stimulation as a tool to excite central terminals of primary afferents expressing TRPM8. LacZ-expressing DH neurons exhibited fast and slow miniature EPSCs. Menthol selectively increased the frequency of the slow mEPSCs in cad $8+1-$ slices, but this effect was abolished in cad8-I- slices. The cad8-I- mice also showed a reduced sensitivity to cold temperature. These results demonstrate that cad8 is essential for establishing the physiological coupling between cold-sensitive sensory neurons and their target $\mathrm{DH}$ neurons.

Key words: cadherin; dorsal horn; menthol; sensory neuron; synapse formation; TRPM8

\section{Introduction}

Cell-cell adhesion molecules are known to regulate synaptic connections. For example, immunoglobulin superfamily proteins, such as sidekicks and Syg-1 and -2, have been shown to control the formation of specific synapses between appropriate cells

\footnotetext{
Received Sept. 6, 2006; revised Feb. 21, 2007; accepted Feb. 21, 2007.

This work was supported by Grants-in-Aid for Specially Promoted Research (M.T.) and Grants-in-Aid for Scientific Research (M.Y., H.F.) of the Ministry of Education, Science, Sports and Culture of Japan, and by a grant from the 21s Century Center of Excellence Program of the Japan Society for the Promotion of Science (M.Y.). We are grateful to $S$ Yonemura and M. F. Uwo for preparing the ultrathin sections; R. Axel and P. Mombaerts for providing the plasmid ETLPA-; Y. Nakahara, R. Suzuki, and Y. Motegi for producing chimera mice; J. Miyazaki for providing CAG Cre transgenic mice; H. Ishigami, C. Yoshii, H. Mizuguchi and the Laboratory for Animal Resources and Genetic Engineering in RIKEN Center for Developmental Biology for the housing of the mice; T. Tabata for technical assistance in analyzing $\mathrm{Ca}^{2+}$ imaging; K. Honda for his advice in behavioral analysis; and T. Manabe for his advice in the early stage of this work.

*S.S. and H.F. contributed equally to this work.

Correspondence should be addressed to either of the following: Dr. Masatoshi Takeichi, RIKEN Center for Developmental Biology, 2-2-3 Minatojima-Minamimachi, Chuo-ku, Kobe 650-0047, Japan, E-mail: takeichi@cdb.riken.jp; or Dr. Hidemasa Furue, Department of Integrative Physiology, Graduate School of Medical Sciences, Kyushu University, 3-1-1 Maidashi, Higashi-ku, Fukuoka 812-8582, Japan, E-mail: furueh@physiol.med.kyushu-u.ac.jp.

DOI:10.1523/JNEUROSCI.0243-07.2007

Copyright $\odot 2007$ Society for Neuroscience $\quad 0270-6474 / 07 / 273466-11 \$ 15.00 / 0$
}

(Yamagata et al., 2002; Shen and Bargmann, 2003; Shen et al., 2004). Classic cadherins, another family of cell-cell adhesion proteins, have also been implicated in synaptic contact formation. The adhesive activities of cadherin are regulated by catenins, which bind the cytoplasmic domain of the cadherins. Both cadherins and catenins are localized in synaptic junctions (Fannon and Colman, 1996; Uchida et al., 1996). When cadherin activities were blocked by the expression of a dominant-negative form of cadherin in cultured hippocampus neurons, synaptogenesis was impaired (Togashi et al., 2002; Bozdagi et al., 2004). The maturation of synapses on dendritic spines was also blocked by genetic ablation of $\alpha \mathrm{N}$-catenin (Abe et al., 2004).

Vertebrate species express $\sim 20$ subtypes of the classic cadherin, and each subtype preferentially binds to the same subtype or other restricted subtypes, thereby conferring selective adhesiveness on cells (Shimoyama et al., 2000). The nervous system expresses most of the classic cadherin subtypes, and some of them have been shown to be localized in synaptic junctions (Takeichi and Abe, 2005). Furthermore, we showed that different cadherin subtypes, such as cadherin- $6,-8$, and -11 , were expressed by distinct neuronal groups in the brain and that their expression pat- 
terns correlated with the connectivity of these neurons (Suzuki et al., 1997; Inoue et al., 1998). From these observations, we proposed that each cadherin subtype might be used for linking a selected set of neurons belonging to the same functional group, because of its homophilic binding specificity. However, the actual roles of each cadherin subtype in synaptic connections remain to be elucidated, although the general importance of classic cadherins for synaptogenesis have been demonstrated by the ubiquitous blocking of multiple cadherin subtypes with dominantnegative cadherin constructs as mentioned above.

To explore the specific functions of cadherin subtypes, we focused on cad8, a type-II classic cadherin, expressed in the spinal cord. We found that cad8 was expressed in restricted laminas of the dorsal horn (DH) of the spinal cord, as well as by a subset of sensory neurons in the dorsal root ganglia (DRGs). In the circuitries organized by neurons of DH and DRGs, small-diameter sensory afferents conveying nociceptive information form synaptic contacts preferentially with the superficial $\mathrm{DH}$, in particular with neurons of the substantia gelatinosa (SG), whereas nonnociceptive information is carried by large-diameter afferents, $\mathrm{A} \beta$ fibers, which terminate in the deeper laminas (lamina III-IV) of the DH. Previous studies have shown that multiple sensory receptors expressed in these primary afferents are specialized to respond only to particular sensory modalities and to act as sensory transducers (Julius and Basbaum, 2001; Tominaga and Caterina, 2004; Wang and Woolf, 2005). The mechanisms as to how these primary afferents are sorted and connected with their specific target DH neurons are, however, largely unknown. The localization of cad8 in the DH suggested its potential role in the synaptic connections between DH neurons and primary afferents. Therefore, we tested this possibility by generating and examining cad 8 knock-out mice. Our results demonstrate that cad8 was preferentially expressed by TRPM8-expressing sensory neurons and that their synaptic transmission at the $\mathrm{DH}$ was impaired in the cad 8 knock-out mice. This is the first demonstration that a type-II cadherin is essential for the activities of a specific neural circuit.

\section{Materials and Methods}

Gene targeting of cad8. A genomic fragment containing the first methionine of cad8 was cloned from a mouse 129Svj genomic library (Stratagene, La Jolla, CA). To delete a genomic fragment corresponding to the first 83 aa of cad8, we created an NcoI site (for taulacZ insertion line) or a $S p h I$ site (for gaplacZ insertion line) at the first methionine, and then a SpeI site just upstream of the splice donor site, by PCR. TaulacZpA modified from ETLpA- (Mombaerts et al., 1996) or gaplacZpA, followed by floxed poly A-less phosphoglycerate kinase (PGK) neo, was inserted into the NcoI-SpeI site or the SphI-SpeI site, respectively. For a negative selection marker, we used the diphtheria toxin A gene B cassette (Yagi et al., 1993). Homologous recombination was performed in an embryonic stem (ES) cell line, E14TG2a. We screened ES cell colonies by Southern blot analysis by using genomic DNA restricted by BglII digestion, probed with a BglII-SphI fragment (see Fig. $1 A$ ). To remove the floxed poly A-less PGK neo, we crossed cad8-/- mice with CAG-Cre transgenic mice (Sakai and Miyazaki, 1997). We confirmed the removal of the floxed poly A-less PGK neo by PCR. Cad $8-/-$ or $+/-$ mice were backcrossed to C57BL/6 at least six times before use.

Genotyping of mice. Genotyping of cad8 mutants was performed by PCR of the tail DNA by using the following four primers: cad8B $\left(5^{\prime}-\right.$ GCTAGCTGAGACGCTCATGGACCTCTGGAC-3'), cad8D (5'-AATGAAGCTTACCCGGCCAACGAGAATCGG-3'), lacZ2 (5'-TGTACTGGAGGCTGAAGTTCAGATGTGCGG-3'), and lacZ4 (5'-TCCATGACCTGACCATGCAGAGGATGATGC- $3^{\prime}$ ). For the wild-type allele, a $252 \mathrm{bp}$ fragment was amplified with cad8B and cad8D. For the targeted cad8 allele, a 390 bp fragment was amplified with lacZ2 and lacZ4.
Animal housing. Animals were housed in environmentally controlled rooms in accordance with the Institute of Physical and Chemical Research (RIKEN) guidelines for animal experiments.

Western blotting. The spinal cord of an adult mouse of each genotype was dissected out and homogenized in $\sim 3$ vol of sample buffer. The amount of proteins in the samples was determined by using Bio-Rad (Hercules, CA) protein assay reagent. Protein samples were subjected to SDS-PAGE (7.5\%) and transferred electrophoretically to a nitrocellulose membrane. The membrane was incubated with anti-cad8 and then with HRP-linked anti-mouse IgG antibodies (GE Healthcare, Piscataway, NJ). Signals were detected by using ECL (GE Healthcare).

Immunohistochemistry. Four $\sim 8$ week old mice were deeply anesthetized with pentobarbital and perfused through the left ventricle with a fixative containing $4 \%$ formaldehyde in $0.1 \mathrm{M}$ phosphate buffer (PB). Segments of spinal cord at the lumbar enlargement were dissect out and then cryoprotected by immersion in $30 \%$ sucrose in $0.1 \mathrm{M} \mathrm{PB}$ at $4^{\circ} \mathrm{C}$, followed by embedding in Tissue Tek OCT compound (Sakura Finetek, Tokyo, Japan). Ten micrometer cryosections were cut with an HM500M cryostat (Microm, Heidelberg, Germany). 5-bromo-4-chloro-3-indolyl$\beta$-D-galactopyranoside (X-gal) staining was performed according to the standard protocol (Hogan et al., 1994). Mouse monoclonal antibody against cad8 (CAD8-1), and rat antiserum against TRPM8 were generated in our laboratory, as described in supplemental Materials and Methods (available at www.jneurosci.org as supplemental material). Specificity of the CAD8-1 and the antiserum against TRPM8 is shown in supplemental Figure 1 (available at www.jneurosci.org as supplemental material). Other reagents used for immunostaining were as follows: rat anti-E-cadherin (ECCD2), mouse anti- $\beta$-galactosidase (Promega, Madison, WI), rabbit anti- $\beta$-galactosidase (purchased from MP Biomedicals, Solom, $\mathrm{OH}$, and affinity purified by ourselves), goat anti- $\beta$-galactosidase (Biogenesis, Poole, UK), rabbit anti-protein kinase C $\gamma$ (PKC $\gamma$; Santa Cruz Biotechnology, Santa Cruz, CA), rabbit anti-TRPV1 (Calbiochem, La Jolla, CA), Isolectin B4 conjugated with FITC (Sigma, St. Louis, MO), Alexa488- or Alexa555-conjugated goat anti-mouse IgG and anti-rabbit IgG (Invitrogen, Eugene, OR), Cy3-conjugated goat anti-rat IgG (Millipore, Temecula, CA), and Cy3-conjugated donkey anti-goat IgG (Jackson ImmunoResearch, West Grove, PA).

Immunoelectron microscopy. Four $\sim 8$ week old mice were deeply anesthetized with pentbarbital and perfused through the left ventricle with a fixative containing $4 \%$ formaldehyde and $0.2 \%$ glutaraldehyde for the detection of taulacZ or gaplacZ or with $4 \%$ formaldehyde for the detection of cad8. Segments of the spinal cord at the lumbar enlargement were dissect out and sliced transversely at a $70 \mu \mathrm{m}$ thickness by using a DTK3000 microslicer (Dosaka, Kyoto, Japan). For the detection of taulacZ or gaplacZ, slices were permeabilized with $0.05 \%$ Triton X-100 for 30 min to enhance penetration of antibodies and incubated with mouse monoclonal antibody against $\beta$-galactosidase (1:5000; Promega) for $3 \mathrm{~d}$ at $4^{\circ} \mathrm{C}$ and overnight with biotinylated Fab fragment of anti-mouse IgG (1:400; Jackson ImmunoResearch) and then with an avidin-biotin-peroxidase complex (1:100 dilution; ABC Elite kit; Vector Laboratories, Burlingame, $\mathrm{CA}$ ) for $1 \mathrm{~h}$ at room temperature. Slices were preincubated for $10 \mathrm{~min}$ in 3, 3-diaminobenzidine (DAB) $[0.05 \%(\mathrm{v} / \mathrm{v})$ in $0.05 \mathrm{M}$ Tris- $\mathrm{HCl}, \mathrm{pH} 7.6]$ and then reacted with $0.05 \%(\mathrm{v} / \mathrm{v})$ DAB with $0.01 \%(\mathrm{v} / \mathrm{v}) \mathrm{H}_{2} \mathrm{O}_{2}$. The reaction product of $\mathrm{DAB}$ was silver-intensified, and then gold toning was performed according to the procedure of Teclemariam-Mesbah et al. (1997). For the detection of cad8, spinal cord slices were incubated with CAD8 -1 for $3 \mathrm{~d}$ at $4^{\circ} \mathrm{C}$, subsequently overnight with anti-mouse IgG conjugated with $1.4 \mathrm{~nm}$ colloidal gold (1:100; Nanoprobes, Stony Brook, $\mathrm{NY}$ ), and then subjected to silver enhancement (HQ silver; Nanoprobes). Stained slices were treated with $0.5 \% \mathrm{OsO}_{4}$ for 30 min and stained en bloc with $4 \%$ uranyl acetate in $50 \%$ ethanol (EtOH). The slices were dehydrated and embedded in Epon812. Parasagittal ultrathin sections were cut at $70 \sim 80 \mathrm{~nm}$ by using an ultramicrotome (Ultracut UCT; Leica, Nussloch, Germany), stained with $4 \%$ uranyl acetate in 50\% EtOH and Leinold's lead citrate, and observed with an electron microscope (JEM1010; JOEL, Tokyo, Japan). Images were acquired by using a Gatan (Pleasanton, CA) Bioscan 792 digital camera.

Electrophysiology. The electrophysiological recordings used for the current experiments were similar to those in our preceding study (Yo- 
shimura and Nishi, 1993). Briefly, a 500- $\mu$ mthick transverse spinal cord slice (prepared from a 5- to 8-week-old mouse) was set in a chamber perfused with Krebs' solution [containing the following (in $\mathrm{mm}$ ): $117 \mathrm{NaCl}, 3.6$ $\mathrm{KCl}, 2.5 \mathrm{CaCl}_{2}, 1.2 \mathrm{MgCl}_{2}, 1.2 \mathrm{NaH}_{2} \mathrm{PO}_{4}, 25$ $\mathrm{NaHCO}_{3}$, and 11 glucose] equilibrated with $95 \% \mathrm{O}_{2}-5 \% \mathrm{CO}_{2}$ at $36^{\circ} \mathrm{C}$. Blind whole-cell voltage-clamp recordings were performed from SG neurons. Patch-pipettes were filled with a solution having the following composition (in $\mathrm{mm}$ ): $135 \mathrm{~K}$-gluconate, $5 \mathrm{KCl}, 0.5$ $\mathrm{CaCl}_{2}, 2 \mathrm{MgCl}_{2}, 5$ EGTA 5 HEPES, and $5 \mathrm{Mg}$ ATP. The pipette resistance was $8-12 \mathrm{M} \Omega$, and the holding potential used was $-70 \mathrm{mV}$. Drugs were dissolved in Krebs' solution and applied by perfusion.

Imaging of intracellular $\mathrm{Ca}^{2+}$ concentration. DRGs were isolated from 5- to 8-week-old mice, incubated at $37^{\circ} \mathrm{C}$ for $20 \mathrm{~min}$ in PBS containing $0.25 \%$ collagenase and $0.25 \%$ trypsin, and dissociated by trituration. Dissociated cells were seeded on poly-L-lysine-coated glass coverslips, and loaded with $2 \mu \mathrm{M}$ Fura-2 acetoxymethyl ester at room temperature for $40 \mathrm{~min}$. The fluorescence ratio (F340/F380) was obtained as the ratio of fluorescence intensity (F340) by $340 \mathrm{~nm}$ excitation to that (F380) by $380 \mathrm{~nm}$ excitation. The intracellular $\mathrm{Ca}^{2+}$ concentration $\left[\mathrm{Ca}^{2+}\right]_{i}$ was calculated by using the equation $\left[\mathrm{Ca}^{2+}\right]_{\mathrm{i}}=K_{\mathrm{d}} \beta\left(R-R_{\min }\right) /(R \max -$ $R$ ), where $K_{\mathrm{d}}$ is the dissociation constant, assumed to be 224 nм (Grynkiewicz et al., 1985). By use of ionomycin, $R_{\max }$ and $R_{\min }$ were obtained at a concentration of $2 \mathrm{mM} \mathrm{Ca}^{2+}$ solution and 5 mm EGTA in $\mathrm{Ca}^{2+}$-free solution, respectively.

Behavioral tests. The method used for measuring cold sensitivity was similar to those described previously (Allchorne et al., 2005). Mice were placed on a cold plate at surface temperatures of 5 or $10^{\circ} \mathrm{C}$, which were controlled by cold water irrigated underneath the plate. Cold sensitivity was determined by measuring the latency to withdraw the hindpaw from the cold stimulus. Thermal sensitivity was measured using a plantar test apparatus (Ugo Basile, Varese, Italy), which focused radiant heat on the plantar surface of the hindpaw of mice. The latency to withdraw the hindpaw from the heat stimulus was measured as the thermal withdrawal threshold. The intensity of the radiant heat was set to obtain baseline latencies around $10 \mathrm{~s}$. Cutoff times used in the cold and thermal tests were 150 and $25 \mathrm{~s}$, respectively, to prevent tissue damage. These behavioral tests were performed blinded to the genotype of the mice used.

Statistical analysis. Data are presented as the mean \pm SEM. Statistical analysis was performed by using a two-tailed Student's $t$ test, Student's paired $t$ test, or one-way ANOVA, and the Kolmogorov-Smirnov test was used for comparing two cumulative distributions.

\section{Results}

\section{Generation of cad8-null mutation by gene targeting}

To disrupt the cad 8 gene, we replaced the genomic fragment corresponding to amino acids $1-83$, containing the signal sequence, with taulac $Z$ or lacZ fused to the membrane-targeting domain of Gap-43 (gaplacZ) (Fig. 1A); insertion of these markers into the targeted cad8 locus allowed us to label the cells and their processes, which had originally expressed cad8 in the knock-out mice. In $c a d 8-/-$ mice, no cad8 protein was detected with antibodies specific for this protein in Western blotting analysis (Fig. 1C). These mutant mice were viable, fertile, and apparently normal, but showed a characteristic behavioral phenotype: they raised the tail, particularly when exposed to stress, for example, when placed on an open-air elevated board (data not shown).

Before phenotypic analysis of the mutant mice, we examined the expression of taulacZ or gaplacZ by conducting X-gal histochemistry on brain slices of $c a d 8+/-$ lines at various developmental stages. The expression patterns of both markers were consistent with those of cad8 mRNA in the wild-type mice, as reported previously (Korematsu and Redies, 1997a,b; Suzuki et al., 1997). Because X-gal reaction products had diffused throughout the entire neuronal cytoplasm, we could trace the neurites of cad8-expressing neurons in both cad $8+/-$ and $-/-$ samples. For detailed analysis, we focused on the central projections of sensory neurons in the DH of the spinal cord. X-gal histochemistry revealed that a small population of small to medium-sized sensory neurons in the DRGs and a subset of neurons in the superficial layers of $\mathrm{DH}$ exhibited $\beta$-galactosidase activity (Fig. $2 A-C)$. Consistent results were also obtained by in situ hybridization (supplemental Fig. 2A,E, available at www.jneurosci.org as supplemental material). Because sensory neurons of these sizes are known to innervate the superficial layers of the $\mathrm{DH}$, we reasoned that cad8 might function in the linkage between cad8expressing sensory neurons and cad8-expressing DH neurons, and we tested this idea by performing the studies described below.

\section{Characterization of cad8-expressing cells in DRGs and spinal cord}

DRG neurons comprise a number of different subtypes. We sought to identify the subtypes of cad8-expressing sensory neurons by double-staining for lacZ and various markers. We used cad8-/- samples for this analysis because lac $Z$ immunosignals were not strong enough in the cad $8+/-$ samples and also because 


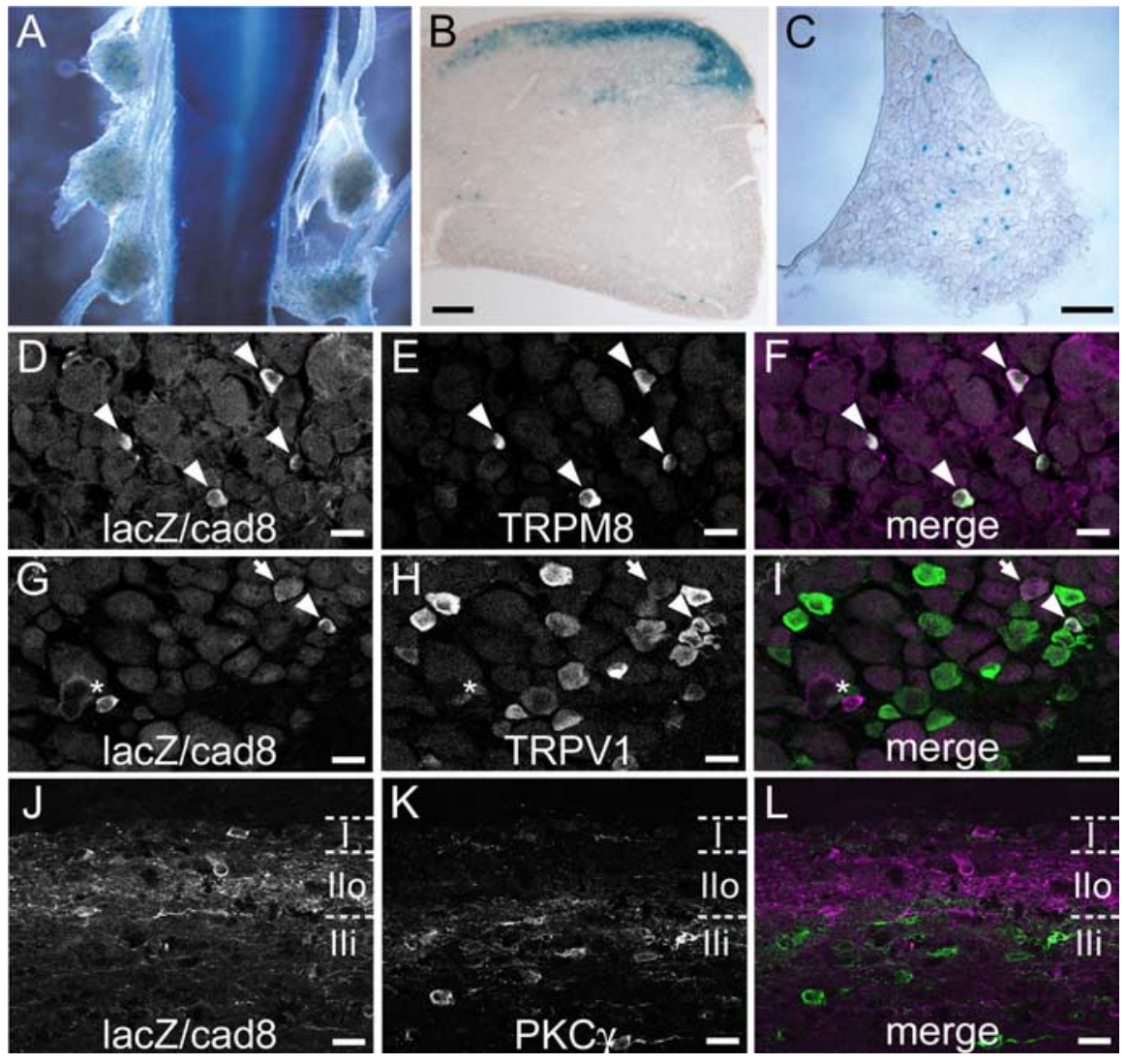

Figure 2. Distribution of lacZ/cad8-expressing neurons in DRG and DH. $\boldsymbol{A}$, Dorsal view of whole-mount, X-gal-stained spinal cord and DRGs of a cad8+I- mouse. $\boldsymbol{B}, \boldsymbol{C}$, A section of $X$-gal-stained spinal cord $(\boldsymbol{B})$ and of a DRG $(\boldsymbol{C})$ from a cad8+I- mouse. $\boldsymbol{D}-\boldsymbol{F}$, A section of DRG, double-immunostained for lacZ (magenta) and TRPM8 (green). Arrowheads indicate sensory neurons expressing both lacZ and TRPM8. G-I, A section of DRG, double-immunostained for lacZ (magenta) and TRPV1 (green). The arrowhead points to a sensory neuron expressing both lacZ and TRPV1, and the arrow indicates a lacZ-positive sensory neuron with weak TRPV1 expression. The asterisk indicates a lacZ-positive sensory neuron without TRPV1 expression. $\boldsymbol{J}-\boldsymbol{L}, \mathrm{A}$ parasagittal section of a cad8+/ - spinal cord, double-immunostained for lacZ (magenta) and PKC $\gamma$ (Green). Most of the lacZ-expressing neurons are located in laminas I and Ilo. LacZ-expressing neurons do not express PKC $\gamma$. Scale bars: B, C, $100 \mu \mathrm{m} ; \boldsymbol{D}-L, 20 \mu \mathrm{m}$.

the number and pattern of lacZ-expressing neurons were not particularly different between the heterozygous and homozygous mutant samples, as revealed by X-gal staining. We found that lacZ-positive neurons constituted $\sim 5 \%$ of the total sensory neuron population in the DRGs, and confirmed that lacZ reactivity was restricted to small to medium-sized neurons in the adult DRGs. After testing markers for different cell types, we noticed that the majority of the lacZ-positive neurons costained with antibodies against TRPM8, a nonselective cation channel gated by menthol and cold temperature (McKemy et al., 2002; Peier et al., 2002) and vice versa (Fig. $2 D-F$ ), that is, $\sim 76 \%$ of the lacZpositive sensory neurons expressed TRPM8, and 73\% of the TRPM8-positive neurons expressed cad8. In addition, we found that $16 \%$ of the cad8-expressing sensory neurons expressed TRPV1, a nonselective cation channel gated by capsaicin and noxious heat (Caterina et al., 1997), and 2\% of the TRPV1positive neurons expressed cad8 (Fig. $2 G-I$ ).

We also characterized cad8-expressing cells residing in the $\mathrm{DH}$. In contrast to the case of the DRGs, anti-lacZ antibodies could detect their immunoreactive signals not only in cad8-/but also in cad8+/ - neurons in DH sections. Most of the cell bodies of the lacZ-positive neurons were situated in lamina I and in the dorsal part of lamina II (lamina IIo), as assessed by doublestaining for PKC $\gamma$, known to label interneurons present in laminas IIi and III (Polgár et al., 1999) (Fig. 2J-L).
Localization of cad8 protein at synapses in synaptic glomeruli of the $\mathrm{DH}$

Next, we examined the localization of cad 8 proteins. In transverse sections of adult spinal cord, cad8 showed a punctuate distribution in the thin superficial layer of the DH at all axial levels (Fig. 3A, and supplemental Fig. $2 I$, available at www.jneurosci.org as supplemental material). Double-staining with anti-cad8 and isolectin B4 (IB4), a marker for the intermediate zone between laminas IIi and IIo (Zylka et al., 2005), revealed that major cad8 protein signals were distributed in the IB4-positive zone, with additional weaker signals below and above this zone (Fig. 3A-C). In parasagittal sections of the superficial $\mathrm{DH}$, we found that punctate signals of cad8 were arranged in oval or horseshoe-like shapes (Fig. 3D, asterisks). To analyze cad8-positive structures in more detail, we double-stained the sections for cad8 and E-cadherin (E-cad). E-cad is known to be localized along axons extending from a subpopulation of smallto medium-sized sensory neurons in the DRGs, but not to be expressed by DH neurons themselves (Shimamura et al., 1992) (see also supplemental Fig. 2C,G, available at www.jneurosci.org as supplemental material); thus, anti-E-cad antibodies decorate axonal shafts and terminals of these DRG sensory neurons, discriminating them from DH neurons (Fig. 3E). Doubleimmunostaining for cad8 and E-cad provided images suggesting that almost all of the oval signals of cad8 were associated with the E-cad-positive axon terminals in the intermediate zone of laminas IIo and IIi and vice versa (Fig. $3 F)$.

To analyze cad8 localization at the ultrastructural level, we used preembedding immunogold electron microscopy. In the $\mathrm{DH}$, axon terminals of sensory neurons form synaptic glomeruli in which a core axonal bouton (C-bouton) is surrounded by several dendritic and axonal processes (Ribeiro-Da-Silva, 2004). The synaptic glomeruli in the DH are classified into two types, I and II: the type I glomeruli are further classified into two subtypes, types Ia and Ib; and the type II is also subdivided into type IIa and type IIb (for anatomical details, see Ribeiro-Da-Silva, 2004). Cad8 protein signals were localized at synaptic clefts formed between a C-bouton and dendritic processes organizing these synaptic glomeruli, or in the vicinity of the synaptic cleft (Fig. 3G,H). Our morphological analysis estimated that $\sim 80 \%$ of the cad8-positive synaptic glomeruli were type Ia, with the other $20 \%$ being type IIa. Because our monoclonal antibody against cad8 recognized the extracellular domain of cad8, we could not determine whether the cad8 signals were derived from the postsynaptic or presynaptic neurons. To clarify this point further, we examined lacZ-staining profiles in the adult cad8+/- spinal cord by preembedding immunoelectron microscopy using the silver-gold intensified DAB reaction (Teclemariam-Mesbah et al., 1997). In labeled synaptic glomeruli, lacZ immunoreactivity was detected not only in dendrites, but also in C-boutons, al- 
though the C-bouton signals were sporadic compared with the dendritic ones, as would be expected from the low sensitivity of immunohistochemical detection of lacZ in $\mathrm{cad} 8+/-$ sensory neurons. Among the lacZ-immunoreactive axons, at least $60 \%$ of them were associated with lacZimmunoreactive dendrites, forming synaptic glomeruli (Fig. 3I,J).

\section{Immunohistochemical analysis of cad8 knock-out spinal cord}

We assessed the effects of $c a d 8$ ablation on the connections between cad8-positive sensory and DH neurons. To evaluate the projection of the originally cad8-positive sensory afferents, we used E-cad instead of lacZ as a marker of sensory afferent terminals because, in the DH, cad8-positive glomeruli generally received E-cad-positive afferent terminals (Fig. $3 F$ ); also, it was difficult to distinguish the lacZ-positive afferent fibers from intermingled neuropils derived from lacZ-positive $\mathrm{DH}$ neurons by lacZ immunostaining. In addition, single-cell PCR revealed that cad8positive DRG neurons coexpressed E-cad, indicating that E-cad can work as a marker of the former (supplemental Fig. 3, available at www.jneurosci.org as supplemental material). However, no significant difference was found in the projection pattern of E-cad-positive afferents into the DH between cad8-/ - and cad8+/- spinal cords (data not shown). Next, we examined lacZ-positive synaptic glomeruli in the adult $\mathrm{DH}$ by preembedding immunoelectron microscopy using the silvergold intensified DAB reaction. Again, no significant difference was found at least in the density of lacZ-positive synaptic glomeruli or in the number of synapses formed in these glomeruli between cad $8-/-$ and $+/-$ samples (Table 1 ). The ratio of the coupling between lacZpositive axons and dendrites also remained similar between them. Because of the morphological complexity in DH synaptic organization, we could not quantitatively evaluate whether the synaptic shape or size was altered or not in the mutant samples.

In the above analysis, we noted that $\beta$ and $\alpha \mathrm{N}$-catenins cadherin-binding proteins were normally localized at the terminals of E-cad-positive axon terminals in cad8-/- mice (data not shown), implying that the loss of cad8 in these synapses is compensated by other classic cadherins. To test this possibility, we examined the expression profile of cadherin-11 (cad11), because this cadherin can heterophilically bind cad8 (Shimoyama et al., 2000). Transcripts of this cadherin were also expressed by small to medium-sized DRG neurons whereas, in contrast to the case of cad8, these transcripts were not detected in the $\mathrm{DH}$ area of the spinal cord (supplemental Fig.
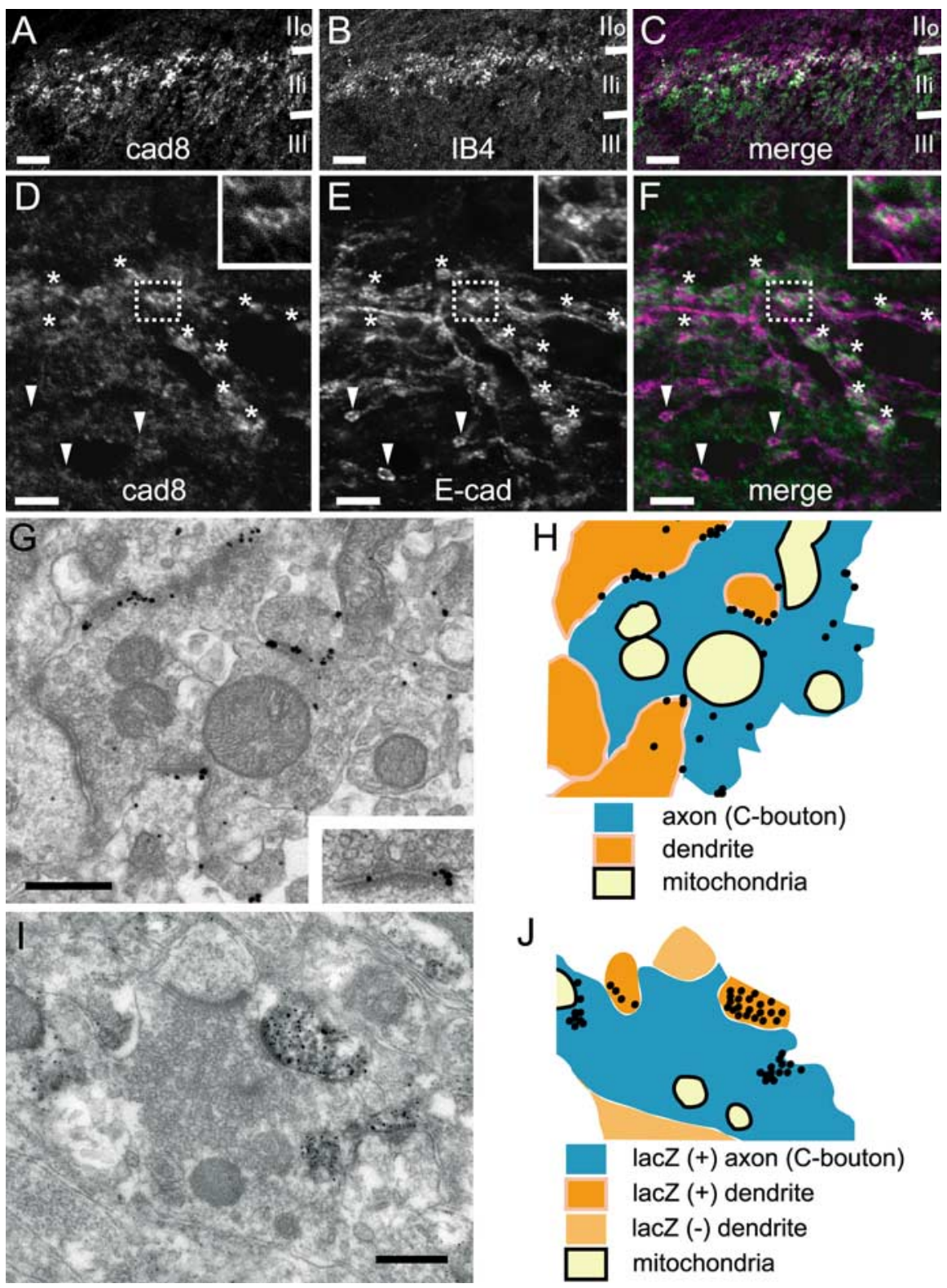

Figure 3. Localization of cad8 protein in the DH. $\mathbf{A}-\mathbf{C}, \mathrm{A}$ transverse section of a DH, double-immunostained for cad8 and IB4 Cad8 signals are localized in a punctate manner and its intense signals are mostly distributed in the IB4-positive layer. $\boldsymbol{D}-\boldsymbol{F}, \mathbf{A}$ parasagittal section of a DH, double-immunostained for cad8 (green) and E-cad (magenta). E-cad is localized along axons and their terminals of only sensory neurons. Asterisks indicate axon terminals, which are double-positive for E-cad and cad8, and arrowheads indicate those that are E-cad positive but cad8 negative. The insets show enlarged images of the boxed areas. $\mathbf{G}, \boldsymbol{H}, \mathrm{An}$ immunoelectron microscopic image of cad8 in a synaptic glomerulus $(\boldsymbol{G})$ and its schematic image $(\boldsymbol{H})$. Immunogold signals are localized at the interfaces between the axon terminal and some of the dendrites attached to it. The inset in $\mathbf{G}$ is an enlarged image of cad8 signals associated with a synaptic junction. $I, J$, An immunoelectron microscopic image of a synaptic glomerulus stained for lacZ $(\boldsymbol{I})$ and its schematic image $(\boldsymbol{J})$. LacZ signals are visualized as black dots, and these are detectable in both axon terminals and some of the associated dendrites. Scale bars: $\boldsymbol{A}-\boldsymbol{C}, 50 \mu \mathrm{m} ; \boldsymbol{D}-\boldsymbol{F}, 5 \mu \mathrm{m} ; \boldsymbol{G}, \boldsymbol{I}, 0.5 \mu \mathrm{m}$.

$2 B, F$, available at www.jneurosci.org as supplemental material). Nevertheless, cad11 protein was detected in the DH with a pattern similar to that of cad8, colocalizing with E-cad (supplemental Fig. 2J-N, available at www.jneurosci.org as supplemental material). These observations suggest that cad11 might be transported to sensory axon terminals, and engage in heterophilic interactions with cad8 or other molecules expressed by DH neurons. We also checked whether cad8-positive DRG neurons expressed any other cadherins by the single-cell PCR method (see supplemental Materials and Methods, available at www. 
Table 1. Summary of the number of glomeruli or synapses formed by cad8-positive dendrites

\begin{tabular}{|c|c|c|c|c|}
\hline Genotype & Type I glomeruli & Type II glomeruli & Unidentified & Total \\
\hline \multicolumn{5}{|c|}{ Synapse-forming structures, containing lacZ-positive dendrites } \\
\hline$+/-(n=5)$ & $11.0 \pm 1.1$ & $1.5 \pm 0.2$ & $18 \pm 1.9$ & $30.5 \pm 2.8$ \\
\hline$-/-(n=5)$ & $10.8 \pm 1.0$ & $1.8 \pm 0.9$ & $23 \pm 2.9$ & $35.6 \pm 1.9$ \\
\hline \multicolumn{5}{|c|}{ LacZ-positive dendritic processes forming synaptic contacts with C-boutons } \\
\hline$+/-(n=5)$ & $15.3 \pm 0.8$ & $2.8 \pm 0.4$ & $18.1 \pm 0.9$ & $36.2 \pm 1.2$ \\
\hline$-/-(n=5)$ & $13.8 \pm 0.9$ & $2.4 \pm 0.6$ & $26.2 \pm 1.2$ & $42.4 \pm 2.2$ \\
\hline
\end{tabular}

LacZ-positive profiles were counted in each $70 \mu \mathrm{m}$ (width) $\times 70 \mathrm{~nm}$ (thickness) parasagittal section prepared from the intermediate mediolateral portion of the spinal cord. The values represent the mean number \pm SEM per section.

A

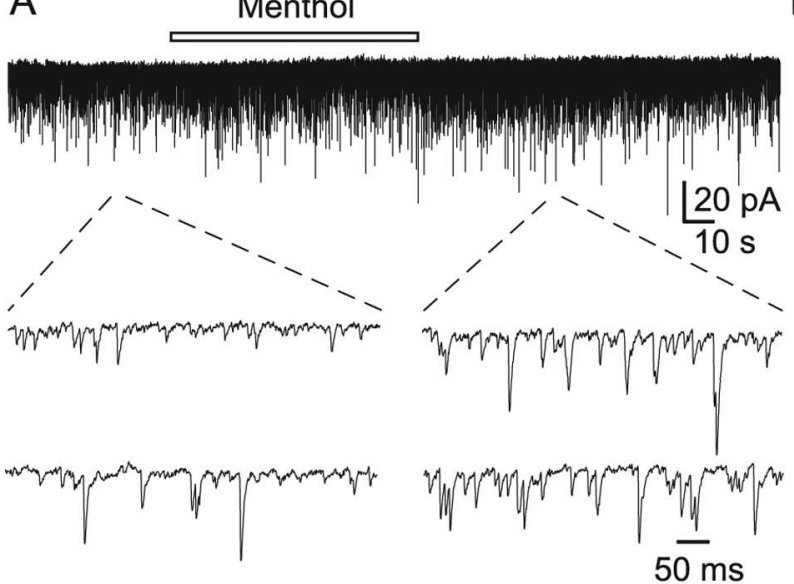

B

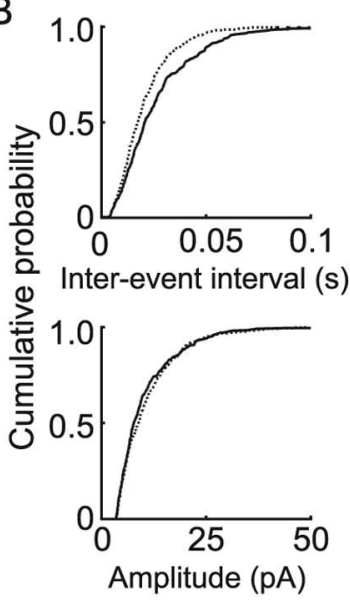

C
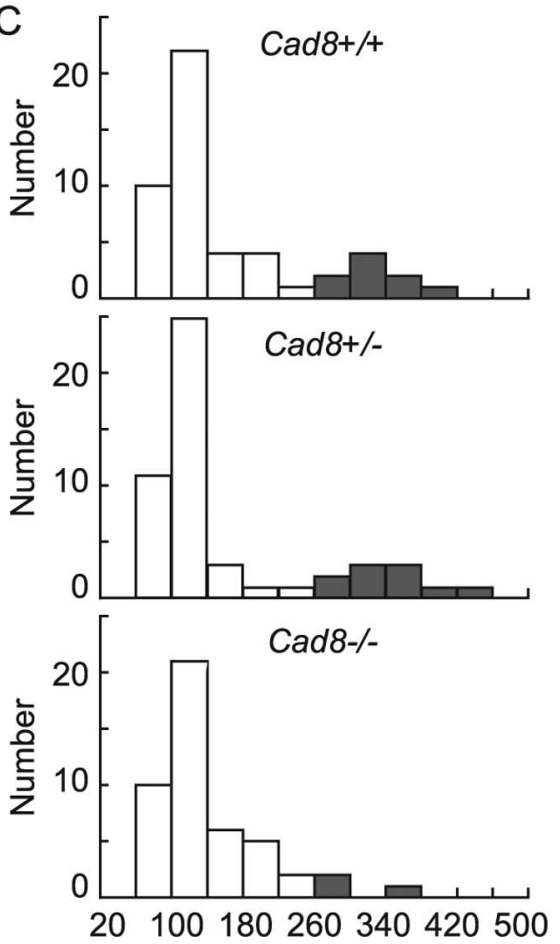

D

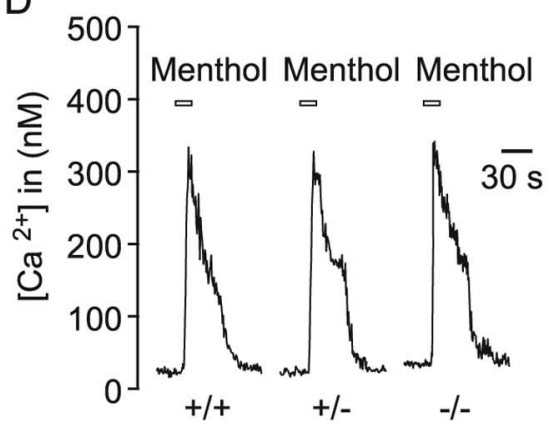

E

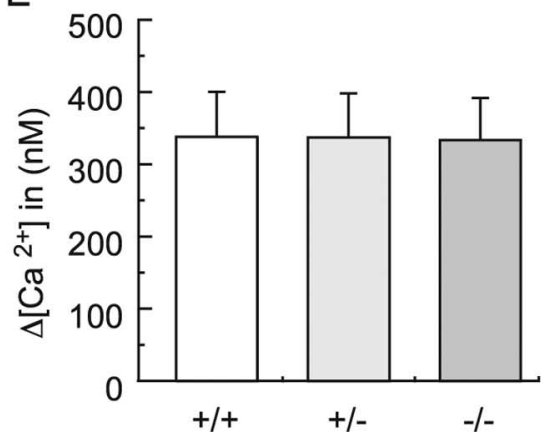

Figure 4. Reduction in synaptic inputs from menthol-sensitive afferent fibers to SG neurons in cad8 - / - slices without changes in the activity of TRPM8. A, Continuous recording of mEPSCs evoked in SG neurons showing the effect of menthol (500 $\mu \mathrm{m})$ in the presence of TTX (1 $\mu \mathrm{M})$. $\boldsymbol{B}$, Cumulative distributions of the interevent interval (top) and amplitude (bottom) of mEPSCs in control (continuous line) and under the action of menthol (dotted line). Data were obtained from the same neuron as shown in $\boldsymbol{A}$. The interevent intervals were significantly reduced under the action of menthol $(p<0.01)$. On the contrary, there is no difference in amplitude between the groups $(p>0.05)$. C, Histograms of the number of neurons plotted against the percentage of frequency of mEPSCs under the action of menthol relative to that in the control (100\%) in cad $8+/+,+/-$, and $-/-$ mice. Closed bars show the numbers of neurons exhibiting an increase to $260 \%$ or more of the control mEPSC frequency. D, Typical examples of increase in intracellular free $\mathrm{Ca}^{2+}$ in DRG neurons of cad8 $+/+,+/-$, and $-/-$ mice in response to menthol (500 $\mu \mathrm{M}) . \boldsymbol{E}$, Summary of menthol-induced increase in intracellular free $\mathrm{Ca}^{2+}$ in DRG neurons of cad $8+1+,+/-$, and $-/-$ mice. There is no difference in the responses to menthol between the groups $(p>0.05)$.

jneurosci.org as supplemental material). Unexpectedly, each of DRG neurons, including cad8-positive ones, expressed a large number of multiple cadherin subtypes, at least in the transcript level, whose combinations varied with the individual neurons (supplemental Fig. 3, available at www.jneurosci.org as supplemental material). Together with the above observation that catenins are normally localized in the $\mathrm{DH}$ without cad8, it is possible that the originally cad8-bearing synapses are retained, having other cadherin subtypes, in the cad $8-/-\mathrm{DH}$, although these results did not exclude the possibility that some of the cad8-expressing afferents might have made incorrect connections with $\mathrm{DH}$ neurons after cad8 ablation.

\section{Reduction in synaptic inputs to $\mathrm{DH}$ neurons from menthol-sensitive afferent fibers in cad8-/- mice} Next, we asked whether the synapses formed in DH neurons with afferent fibers were functionally normal or not in cad8-/ - mice by comparing the action of menthol on synaptic transmission to SG neurons in cad $8+/+,+/-$, and $-/-$ mice, because most cad8-expressing DRG neurons had TRPM8, and menthol was reported to enhance transmitter release through the activation of TRPM8 expressed in central terminals of afferent fibers (Baccei et al., 2003; Tsuzuki et al., 2004). Application of menthol facilitated the frequency of miniature EPSCs (mEPSCs) in a subpopulation of SG neurons. The amplitude of mEPSCs was not changed (Fig. $4 A, B$ ), suggesting that menthol acted presynaptically to facilitate glutamate release. Menthol is reported to act not only on TRPM8, but also TRPA1 (Macpherson et al., 2006) and voltagegated $\mathrm{Ca}^{2+}$ channels (Swandulla et al., 1987) in sensory neurons. It seems, however, that the facilitation of miniature release by menthol is mainly because of activation of TRPM8 expressed in afferent fibers as reported previously (Baccei et al., 2003; Tsuzuki et al., 2004; Premkumar et al., 2005), because menthol actions on TRPA1 and voltage-gated $\mathrm{Ca}^{2+}$ channels 
are inhibition, contrary to the agonistic effect on TRPM8. The population of SG neurons that exhibited the facilitated miniature release by menthol was relatively reduced in cad $8-/-$ mice (Fig. $4 C$, compare histograms). In cad $8+/+$ and $+/-$ mice, the number of neurons exhibiting a 2.6-fold or more increase in mEPSC frequency was nine $(18 \%)$ of 50 and $11(21 \%)$ of 51 neurons, respectively; however, that in cad8-/- mice was only three $(6 \%)$ of 46 neurons.

To exclude the possibility that the decrease in the number of SG neurons that responded to menthol was caused by a reduction of the TRPM 8 activity in the primary afferents of cad $8-/-$ mice, we next compared the activities of TRPM 8 among cad $8+/+$, $+/-$, and $-/-$ mice by measuring the responses of the intracellular free $\mathrm{Ca}^{2+}$ concentration $\left(\left[\mathrm{Ca}^{2+}\right]_{\mathrm{i}}\right)$ to menthol (Peier et al., 2002) in dissociated DRG neurons. In cad $8+/+$ and $+/-$ neurons, high $\mathrm{K}^{+}(30 \mathrm{~mm})$, used to identify excitable cells, evoked a $\left[\mathrm{Ca}^{2+}\right]_{\mathrm{i}}$ increase in 56 of 70 and 55 of 67 cells, respectively. High $\mathrm{K}^{+}$-sensitive neurons were subsequently tested by menthol application. Ten cells from each of the high $\mathrm{K}^{+}$-sensitive neurons responded to menthol with an increase in $\left[\mathrm{Ca}^{2+}\right]_{\mathrm{i}}$ neurons. Of the cad8-/ neurons $(n=68), 54$ of them responded to high $\mathrm{K}^{+}$. Nine of these 54 neurons were sensitive to menthol. There were no significant differences in basal $\left[\mathrm{Ca}^{2+}\right]_{\mathrm{i}}(\mathrm{cad} 8+/+$, $67.2 \pm 8.9 \mathrm{nM}, n=56$; cad8+/-, $66.6 \pm 6.9 \mathrm{nM}, n=55$; cad8-/-, $65.7 \pm 9.5 \mathrm{nM}, n=54 ; p>0.05)$ and amplitudes of high $\mathrm{K}^{+}$responses $(\mathrm{cad} 8+/+, 347.2 \pm 23.3 \mathrm{nM}, n=56$; cad8+/-, $347.1 \pm 39.3 \mathrm{nM}, n=55 ; \mathrm{cad} 8-/-, 343.6 \pm 35.7 \mathrm{~nm}$, $n=54 ; p>0.05)$ between cad $8+/+,+/-$, and $-/-$ neurons. Responses to menthol were also not significantly different between them $(\mathrm{cad} 8+/+, 337.9 \pm 62.9 \mathrm{nM}, n=10$; $\mathrm{cad} 8+/-$, $336.2 \pm 65.0 \mathrm{nM}, n=9 ;-/-, 334.5 \pm 58.1 \mathrm{nM}, n=8$ ) (Fig. $4 D, E)$. These data suggest that TRPM8 activities were not altered by cad8 deficiency, thus supporting the hypothesis that cad8expressing SG neurons make synaptic contacts with TRPM8expressing afferents and the deletion of cad8 impairs their functions. To further test this hypothesis, we identified individual lacZ-positive SG neurons and examined the action of menthol on their synaptic transmission.

\section{Functional connection between menthol-sensitive afferents and lacZ-positive SG neurons, and decrease in the miniature release in cad8-/- mice}

After examination of the effect of menthol on synaptic transmission in SG neurons, we performed double-staining for intrasomatically injected neurobiotin as a marker of recorded neurons and for lacZ. In cad8+/- mice, 23 cells were successfully stained with neurobiotin. Five of these SG neurons $(21 \%$ of the total neurons) were positive for lacZ, and in these neurons, menthol increased the frequency of mEPSCs $(295.2 \pm 38.8 \%$ of control, $n=5$ ) (Fig. $5 A, B, E$ ). In the remaining $18 \mathrm{SG}$ neurons that were negative for lac $Z$, menthol did not change the mEPSC frequency $(107.2 \pm 11.1 \%$ of control; $p>0.05)$. Menthol did not alter the amplitude of mEPSCs in either lacZ-positive or -negative neurons (lacZ-positive, $119.6 \pm 17.7 \%$ of control; lacZ-negative, $99.4 \pm 6.6 \%$ of control; $p>0.05)$. In $c a d 8-/-$ mice $(n=22)$, on the contrary, menthol did not change the mEPSC frequency in the five SG neurons that were lacZ-positive $(112.9 \pm 25.3 \%$ of control; $n=5 ; p>0.05$ ) (Fig. $5 C, D$ ). The menthol-mediated increase in mEPSC frequency was, thus, significantly suppressed in the lacZ-positive SG neurons of cad8-/- mice (Fig. $5 F$ ). These results confirmed the impaired synaptic inputs from TRPM8-expressing afferents to SG neurons in the mutant mice.
Impairment of the selective enhancement of miniature release of slow EPSCs by menthol in lacZ-positive SG neurons of cad8-/- mice

Next, we analyzed the kinetics of mEPSCs observed in lacZpositive SG neurons and found that fast and slow mEPSCs were detected in single SG neurons (Fig. 6A). Both mEPSCs were sensitive to the AMPA receptor antagonist CNQX $(10 \mu \mathrm{M})$ (data not shown), and no slow inward currents were observed, suggesting that these neurons received glutamatergic inputs, as shown in our previous study (Furue et al., 1999). As seen in Figure 6B, the fast EPSCs had shorter rise times and decay-time constants (20-80\% rise times, $0.24 \mathrm{~ms}$; decay-time constants, $3.1 \mathrm{~ms}$ ) than the slow mEPSCs (20-80\% rise times, $0.73 \mathrm{~ms}$; decay-time constants, 5.5 $\mathrm{ms})$. There was a lack of correlation between the rise-time and amplitude of individual mEPSCs (Fig. 6C). In all cells examined, the $r^{2}$ value of the linear regression for the rise time versus amplitude was $\ll 0.05$ (mean number of mEPSCs per cell was $752 \pm$ $240 ; n=5$ ), suggesting that the difference between the fast and slow EPSCs was not caused by any difference in the distances of the synapses from the soma. The histogram of the rise-time distribution also revealed that two main groups of mEPSCs were present in the single SG neurons (Fig. $6 D$, top). Under the action of menthol, however, the slow mEPSCs were evoked at a higher frequency than in the control (Fig. $6 D, E$, middle). However, the fast EPSCs were observed at almost the same frequency as in control. The rise-time distribution in the presence of menthol showed that menthol mainly increased the number of events with slow kinetics (fast mEPSCs, $107.2 \pm 8.9 \%$ of control, $n=5$; slow mEPSCs, $328.4 \pm 52.6$ of control, $n=5$ ) (Fig. 6 F). In cad $8-/-$ slices, lacZ-positive SG neurons also exhibited fast and slow EPSCs (Fig. $6 D$, bottom, $G$ ). The histogram of the rise-time distribution in cad8-/- samples, however, indicated that the population of mEPSCs with slow kinetics was smaller than that in the cad $8+/-$ ones. The frequency of the slow mEPSCs in cad $8-/-$ neurons was significantly decreased $(\mathrm{cad} 8+/-, 3.1 \pm 0.9 \mathrm{~Hz}, n=$ 5 ; cad8-/ $-, 0.7 \pm 0.3 \mathrm{~Hz}, n=5$ ) (Fig. $6 \mathrm{H}$ ). These results suggest that miniature release from menthol-sensitive afferents evoked slow mEPSCs in cad8-expressing SG neurons and that the deletion of cad8 resulted in a functional loss of the slow synaptic miniature release.

\section{No alteration in synaptic inputs to $\mathrm{DH}$ neurons from capsaicin-sensitive afferent fibers in cad8-/- mice}

Next we compared capsaicin action on mEPSCs evoked in SG neurons between $\mathrm{cad} 8+/+$ and $-/-$ mice. As shown in previous studies (Yang et al., 1998; Baccei et al., 2003), capsaicin acts presynaptically to facilitate glutamate release toward SG neurons. Application of capsaicin increased the frequency, but not the amplitude, of mEPSCs in 11 of 15 SG neurons in cad $8+/+$ mice. Similar action of capsaicin was observed in 11 of 14 SG neurons in cad8-/- mice (supplemental Fig. 4A-D, available at www. jneurosci.org as supplemental material). There was no significant difference in the capsaicin-induced increase in mEPSC frequency between the two groups (supplemental Fig. $4 E$, available at www.jneurosci.org as supplemental material). These negative results can be explained by two alternative ways: first, cad8 is not essential for synaptic inputs to SG neurons from capsaicinsensitive afferent fibers. Second, because only a minor population of DRG neurons coexpresses cad8 and TRPV1, we simply could not detect the effects of cad8 removal on capsaicin sensitivity. 

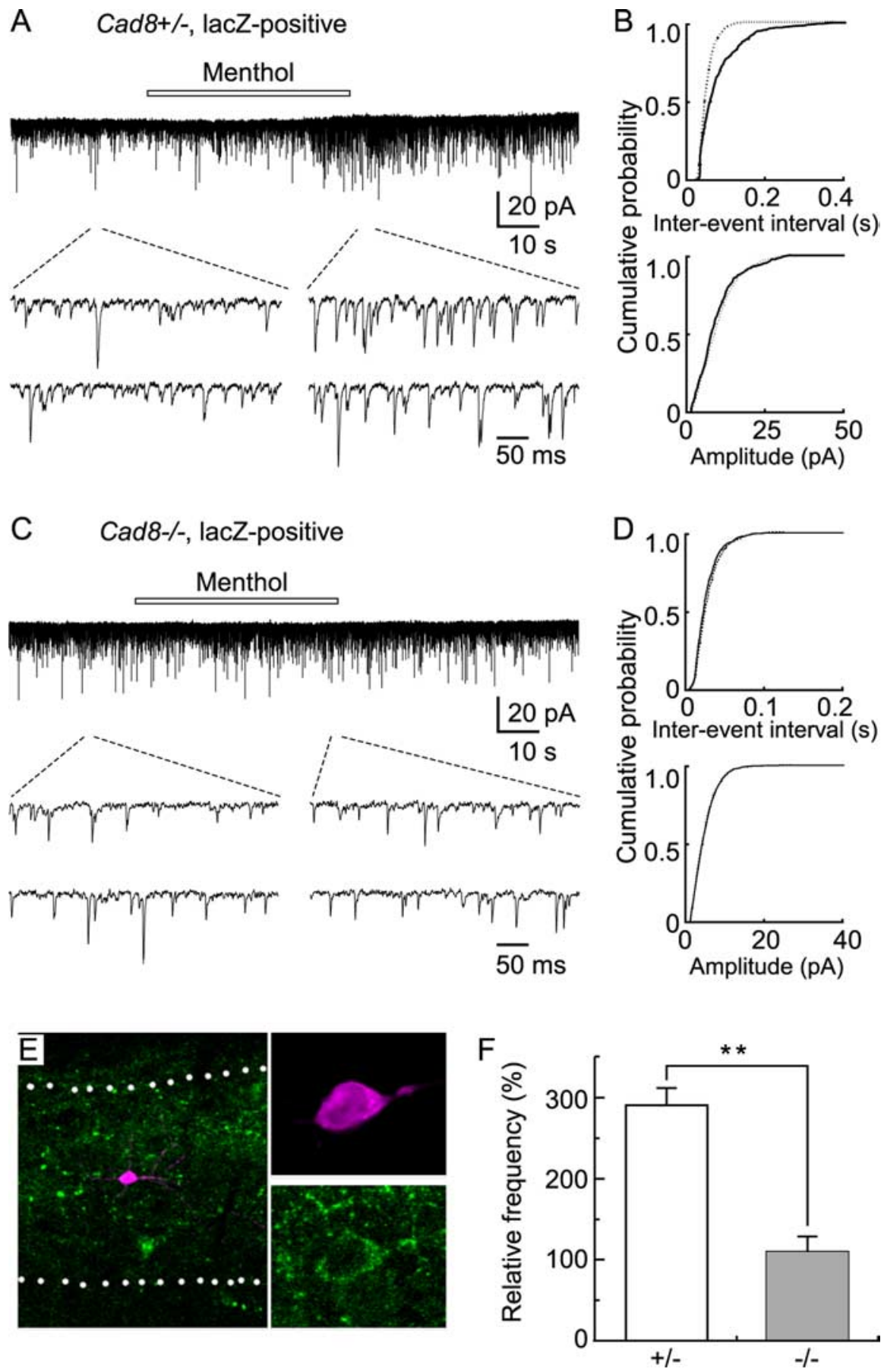

Figure 5. Loss of synaptic inputs from menthol-sensitive (TRPM8-expressing) afferent fibers to lacZ/cad8-expressing SG neurons in cad8 - / - slices. $A, C$, Action of menthol on mEPSCs in lacZ-positive SG neurons in cad8 $+/-(\boldsymbol{A})$ and $-1-(\boldsymbol{C})$ samples. $B, D$, Cumulative distributions of the interevent interval and amplitude of $m E P S C s$ in control (continuous line) and under the action of menthol (dotted line) in cad8 $+/-(\boldsymbol{B})$ and $-/-(\boldsymbol{D})$ samples. Data in $\boldsymbol{B}$ and $\boldsymbol{D}$ were obtained from the same neuron as shown in $\boldsymbol{A}$ and $C$, respectively. The interevent intervals were significanly reduced under the action of menthol in cad $8+/-$, but not in $-/-$ mice $(p<0.01)$. There is no difference in amplitude in cad8 $+/-$ and $-/-$ mice $(p>0.05)$. $\boldsymbol{E}$, Double-staining of a recorded neuron by intrasomatic injection of neurobiotin (magenta) and subsequent treatment with anti-lacZ antibodies (green). Data shown in $A$ were obtained from the same neuron. $F$, Summary showing the reduction in menthol-induced increase in $\mathrm{mEPSC}$ frequency in cad $8-1-$ mice $\left({ }^{* *} p<0.01\right)$.

Reduced behavioral responses to cold, but not thermal stimuli in cad8-/- mice

On the basis of the above electrophysiological results, we considered that cad8-1- mice might exhibit some behavioral changes in response to cutaneous natural stimuli, which causes an activation of afferent fibers expressing TRPM8. We therefore studied cold sensitivity of cad $8+/+$ and $-/-$ mice by quantitative measurement of a withdrawal response to cold stimuli (Allchorne et al., 2005). In cad8+/+ mice $(n=10)$, average latencies to withdrawal at cold-plate surface temperatures of 10 and $5^{\circ} \mathrm{C}$ were $122.8 \pm 8.4$ and $80.7 \pm$ $15.4 \mathrm{~s}$, respectively. These values were compatible with those in rats shown in the previous study. In cad $8-/-$ mice $(n=$ $10)$, the average latencies tended toward longer times at each temperature (Fig. $7 A$ ). In most mice, the cold stimulus at $10^{\circ} \mathrm{C}$ did not elicit any withdrawal responses within a cutoff time of $150 \mathrm{~s}$ (the average latency was $140.4 \pm 4.9 \mathrm{~s}$ ). In response to $5^{\circ} \mathrm{C}$ stimulus, the average latency in cad8-/- mice $(124.4 \pm 14.3 \mathrm{~s})$ was significantly longer than that in cad $8+/+$ mice. Contrary to cold sensitivity, the latency to respond to thermal stimulus (a planter test) did not differ between cad $8+/+$ and cad $8-/-$ mice (Fig. $7 B$ ). The average latencies in $c a d 8+/+$ and cad $8-/-$ were $8.7 \pm 0.8(n=8)$ and $8.8 \pm$ $0.7 \mathrm{~s}(n=8)$, respectively. These results confirm that cad8-deficient mice display decreased sensitivity to cutaneous cold stimuli but not thermal stimuli.

\section{Discussion}

We demonstrated that cad8 was expressed in a restricted zone of the $\mathrm{DH}$, which corresponded to a part of the $S G$, as well as in a small subset of sensory neurons, and that these cad8-positive sensory neurons and cad8-positive SG dendrites formed synaptic contacts with each other by organizing synaptic glomeruli. Furthermore, the majority of the cad8-positive sensory neurons coexpressed TRPM8. These observations suggest that, via its homophilic binding nature, cad8 plays a role in synaptic coupling between the cold-sensitive sensory afferents and their targets. This hypothesis was tested by anatomical and electrophysiological analyses of cad 8 knock-out mice.

We can postulate at least two potential roles of cad8 in synaptic connections. First, its homophilic binding specificity may have an instructive role in the linking of TRPM8-positive sensory neurons and their targets. Our immunoelectron microscopical analysis, however, could not detect any significant difference in the number of lacZ/cad8-positive dendrites coupled with lacZ/cad8-positive sensory terminals between cad $8-1-$ and $+/-$ samples. This result suggests that cad8 is dispensable for synapse formation between these sets of sensory and SG neurons, at least from the anatomical viewpoint. The other hypothetical role for cad8 is to control physiological functions of the synapses formed by TRPM 8 sensory terminals. In this case, the homophilic bind- 
ing nature of cad8 would still be used for pairing a specific set of neurons. Wholecell patch-clamp recordings confirmed that cad8/TRPM8-positive sensory neurons were preferentially and physiologically connected with cad8-positive SG neurons. Genetic ablation of cad8 did not affect the function of TRPM8, but did impair synaptic transmission from the TRPM8-positive sensory afferents to SG neurons. Examination of mEPSC kinetics revealed that two types of mEPSCs, slow and fast EPSCs, were recorded from lacZpositive SG neurons of cad $8+/-$ slices and that the frequency of the slow mEPSCs did not increase in response to menthol stimulation in cad8-/- lacZ-positive SG neurons. Furthermore, cad $8-/-$ mice were less sensitive to cold temperature. Together, our results demonstrate that a group of neurons residing in the DRGs and SG, which had originally expressed cad8, could form synaptic contacts in the absence of cad8, but that the physiological function of these synapses was impaired, thus supporting the second hypothesis.

How might cad8 control synaptic transmission? The reduced frequency of menthol-activated mEPSCs in the lacZpositive neurons of $c a d 8-/-$ DH can be explained in terms of either presynaptic or postsynaptic defects. Previous analysis of $\mathrm{N}$-cadherin-deficient embryonic stem cell-derived neurons revealed that synapses formed between these neurons were morphologically normal, but feeding of synaptic vesicles was impaired during enhanced synaptic activity, leading the authors to conclude that $\mathrm{N}$-cadherin plays a role in facilitating synaptic vesicle release (Jüngling et al., 2006). It was also shown that conditional removal of $\beta$-catenin, a partner of cadherins, from hippocampal pyramidal neurons resulted in a decrease in the number of synaptic vesicles in the undocked pool (Bamji et al., 2003). Cad8 might have a similar presynaptic role, that is, in its absence, release of synaptic vesicles in the axons of TRPM8-positive sensory neurons might have been impaired. We, however, did not particularly observe significant changes in synaptic vesicle density or distribution in the cad8-/- DH (data not shown); thus, the above hypothesis needs additional tests. With regard to the potential postsynaptic defects, we could postulate that cad8 might regulate the activities of specific AMPA receptors, which carry slow mEPSCs, and that loss of cad8 results in dysfunction of these receptors. However, we could not find any correlation between the expressions of cad8 and various AMPA receptor subtypes (supplemental Fig. 5, available at www.jneurosci.org as supplemental material), nor find any suppression of their expression in $c a d 8-/-$ spinal cords (data not shown). As an alternative mechanism, cad8 deficiency could have decreased synaptic size, resulting in the reduced mEPSCs frequency, as found in hippocampal neurons expressing
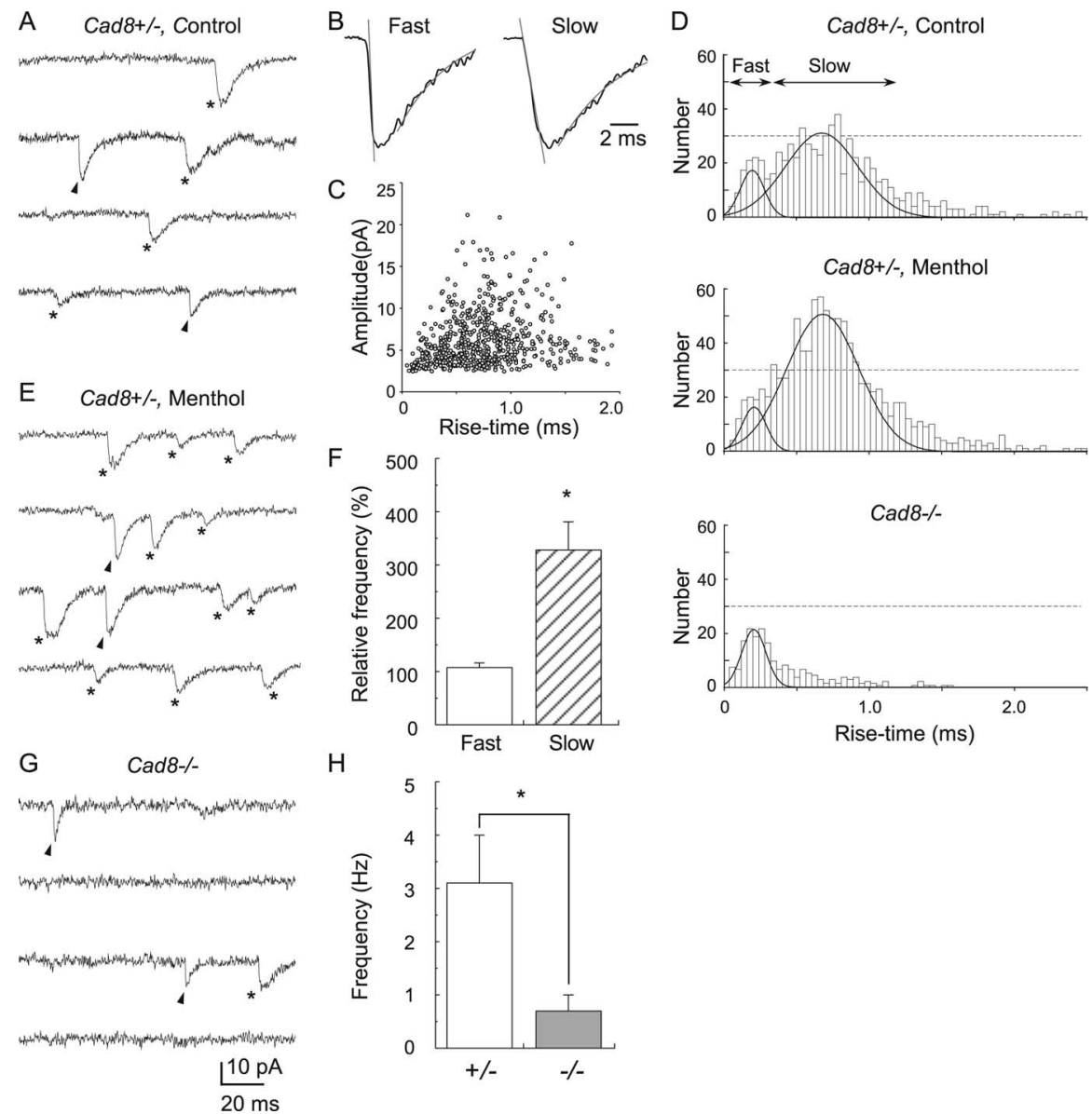

Figure 6. Decrease in frequency of mEPSCs with slow kinetics in lacZ/cad8-expressing SG neurons of cad8 - / - mice. $\boldsymbol{A}$, Typical EPSCs (left trace) and slow mEPSCs (right trace). The rise times and decay-time constants for the fast and slow mEPSCs are 0.24 ( $0.73 \mathrm{~ms}$, and 3.1 and $5.5 \mathrm{~ms}$, respectively. $C$, Plot of peak amplitude versus rise time of $\mathrm{mEPSC}$. Data in $A-C$ were obtained sample, Gaussian curves in each histogram in control and under the action of menthol were fitted to the dominant distribution peaks at 0.20 and $0.68 \mathrm{~ms}$. Menthol increases the number of mEPSCs with slow kinetics, but not that of those with fast kinetics. In the cad8 - / - sample, a Gaussian curve was fitted to the dominant distribution peak at $0.20 \mathrm{~ms}$. The number of slow EPSCs is shown in $\boldsymbol{A}$. Note that slow mEPSCs are evoked at a higher frequency compared with those in the control. $\boldsymbol{F}$, Summary showing that

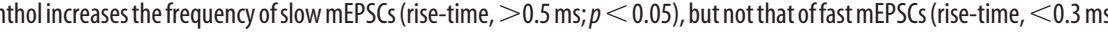
in lacZ-positive neurons of cad8+/- mice. G, Typical traces of mEPSCs with fast and slow kinetics evoked in lacZ-positive neuron of a cad8- - mouse. $\boldsymbol{H}$, Summary showing the decrease in frequency of slow mEPSCs evoked in lacZpositive neurons of $c a d 8-1-$ mice $\left({ }^{*} p<0.05\right)$.

dominant-negative cadherin (Bozdagi et al., 2004). Additional analyses, however, are necessary to convincingly explain the cellular and molecular basis of how cad8 regulates mEPSC frequencies.

Our results demonstrated that cad8-positive sensory neurons expressed nearly 10 classic cadherin subtypes together, consistent with the previous study that neurons express multiple cadherins (Heyers et al., 2004). This finding suggested that other cadherins were still present in the synaptic contacts from which cad8 had been deleted, and redundantly maintained the structure of the synaptic junctions. Indeed, $\beta$ - and $\alpha \mathrm{N}$-catenin, ubiquitously associating with neuronal classic cadherins, were normally detected in the $\mathrm{DH}$ of cad8-/- mice, suggesting that the loss of cad8 was compensated by other cadherins. Among the cadherins expressed in cad8-positive sensory neurons, E-cad and cad11 are assumed 

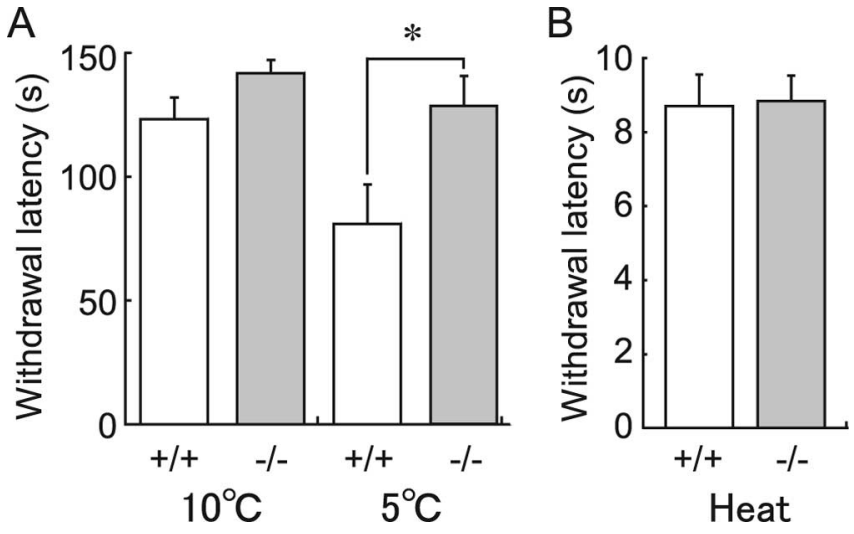

Figure 7. Impaired behavioral response to cold but not thermal stimulus in cad8 $8-1-$ mice. $A$, Withdrawal latency in a cold plate test at the surface temperature of 10 and $5^{\circ} \mathrm{C}$. At $5^{\circ} \mathrm{C}$, the latency in cad8 $-1-$ was significantly longer than that in cad8 $+/+\left({ }^{*} p<0.05\right)$. B, Withdrawal latency in response to a radiant heat stimulus. There is no significant difference in the latency between cad $8+/+$ and $-/-$ mice.

to have no such roles, because they were not expressed in the DH. To identify the cadherin subtypes to compensate for the cad8 loss is therefore a future subject.

Despite the hypothetical presence of multiple cadherins in the synapses of a single neuron, cad8-deficient synapses were functionally abnormal, suggesting that cad8 has a unique physiological function that could not be replaced by other classic cadherins. It was shown that different classic cadherins confer different adhesive strengths at cell junctions (Chu et al., 2006). Although the status of cad8 from this aspect is unknown, such differences imply that classic cadherin subtypes are functionally not identical. In support of this notion, Nand E-cadherin are not interchangeable in the process of retinal axon targeting in the Drosophila visual system (Prakash et al., 2005). Some yet-unidentified nature specific to cad $8 \mathrm{might}$ specifically be required for the terminal activities of TRPM8expressing neurons.

Meanwhile, we cannot completely exclude the potential instructive role of cad 8 in the preferential attachment between a subpopulation of primary afferent fibers and SG neurons. In cad8 mutants, although the originally cad8-positive sensory afferent fibers could form synapses with SG neurons, they might have innervated ectopic partners as a result of cad8 deficiency. This was not tested in the present study. Such possibilities could be examined by using other neuronal marking systems.

\section{References}

Abe K, Chisaka O, Van Roy F, Takeichi M (2004) Stability of dendritic spines and synaptic contacts is controlled by alpha $\mathrm{N}$-catenin. Nat Neurosci 7:357-363.

Allchorne AJ, Broom DC, Woolf CJ (2005) Detection of cold pain, cold allodynia and cold hyperalgesia in freely behaving rats. Mol Pain 1:36.

Baccei ML, Bardoni R, Fitzgerald M (2003) Development of nociceptive synaptic inputs to the neonatal rat dorsal horn: glutamate release by capsaicin and menthol. J Physiol (Lond) 549:231-242.

Bamji SX, Shimazu K, Kimes N, Huelsken J, Birchmeier W, Lu B, Reichardt LF (2003) Role of beta-catenin in synaptic vesicle localization and presynaptic assembly. Neuron 40:719-731.

Bozdagi O, Valcin M, Poskanzer K, Tanaka H, Benson DL (2004) Temporally distinct demands for classic cadherins in synapse formation and maturation. Mol Cell Neurosci 27:509-521.

Caterina MJ, Schumacher MA, Tominaga M, Rosen TA, Levine JD, Julius D (1997) The capsaicin receptor: a heat-activated ion channel in the pain pathway. Nature 389:816-824.
Chu YS, Eder O, Thomas WA, Simcha I, Pincet F, Ben-Ze'ev A, Perez E, Thiery JP, Dufour S (2006) Prototypical type I E-cadherin and type II cadherin-7 mediate very distinct adhesiveness through their extracellular domains. J Biol Chem 281:2901-2910.

Fannon AM, Colman DR (1996) A model for central synaptic junctional complex formation based on the differential adhesive specificities of the cadherins. Neuron 17:423-434.

Furue H, Narikawa K, Kumamoto E, Yoshimura M (1999) Responsiveness of rat substantia gelatinosa neurones to mechanical but not thermal stimuli revealed by in vivo patch-clamp recording. J Physiol (Lond) 521:529-535.

Grynkiewicz G, Poenie M, Tsien RY (1985) A new generation of $\mathrm{Ca}^{2+}$ indicators with greatly improved fluorescence properties. J Biol Chem 260:3440-3450.

Heyers D, Luksch H, Redies C (2004) Selective synaptic cadherin expression by traced neurons of the chicken visual system. Neuroscience 127:901-912.

Hogan BBR, Constantini F, Lacy E (1994) Manipulating the mouse embryo, a laboratory manual, Ed 2. New York: Cold Spring Harbor Laboratory.

Inoue T, Tanaka T, Suzuki SC, Takeichi M (1998) Cadherin-6 in the developing mouse brain: expression along restricted connection systems and synaptic localization suggest a potential role in neuronal circuitry. Dev Dyn 211:338-351.

Julius D, Basbaum AI (2001) Molecular mechanisms of nociception. Nature 413:203-210.

Jüngling K, Eulenburg V, Moore R, Kemler R, Lessmann V, Gottmann K (2006) N-cadherin transsynaptically regulates short-term plasticity at glutamatergic synapses in embryonic stem cell-derived neurons. J Neurosci 26:6968-6978.

Korematsu K, Redies C (1997a) Restricted expression of cadherin-8 in segmental and functional subdivisions of the embryonic mouse brain. Dev Dyn 208:178-189.

Korematsu K, Redies C (1997b) Expression of cadherin-8 mRNA in the developing mouse central nervous system. J Comp Neurol 387:291-306.

Macpherson LJ, Hwang SW, Miyamoto T, Dubin AE, Patapoutian A, Story GM (2006) More than cool: promiscuous relationships of menthol and other sensory compounds. Mol Cell Neurosci 32:335-343.

McKemy DD, Neuhausser WM, Julius D (2002) Identification of a cold receptor reveals a general role for TRP channels in thermosensation. Nature 416:52-58.

Mombaerts P, Wang F, Dulac C, Chao SK, Nemes A, Mendelsohn M, Edmondson J, Axel R (1996) Visualizing an olfactory sensory map. Cell 87:675-686.

Peier AM, Moqrich A, Hergarden AC, Reeve AJ, Andersson DA, Story GM, Earley TJ, Dragoni I, McIntyre P, Bevan S, Patapoutian A (2002) A TRP channel that senses cold stimuli and menthol. Cell 108:705-715.

Polgár E, Fowler JH, McGill MM, Todd AJ (1999) The types of neuron which contain protein kinase $\mathrm{C}$ gamma in rat spinal cord. Brain Res 833:71-80.

Prakash S, Caldwell JC, Eberl DF, Clandinin TR (2005) Drosophila $\mathrm{N}$-cadherin mediates an attractive interaction between photoreceptor axons and their targets. Nat Neurosci 8:443-450.

Premkumar LS, Raisinghani M, Pingle SC, Long C, Pimentel F (2005) Downregulation of transient receptor potential melastatin 8 by protein kinase C-mediated dephosphorylation. J Neurosci 25:11322-11329.

Ribeiro-Da-Silva A (2004) Substantia gelatinosa of the spinal cord. In: The rat nervous system, Ed 3 (Paxinos G, ed), pp 443-494. New York: Academic.

Sakai K, Miyazaki J (1997) A transgenic mouse line that retains Cre recombinase activity in mature oocytes irrespective of the cre transgene transmission. Biochem Biophys Res Commun 237:318-324.

Shen K, Bargmann CI (2003) The immunoglobulin superfamily protein SYG-1 determines the location of specific synapses in C. elegans. Cell 112:619-630.

Shen K, Fetter RD, Bargmann CI (2004) Synaptic specificity is generated by the synaptic guidepost protein SYG-2 and its receptor, SYG-1. Cell 116:869-881.

Shimamura K, Takahashi T, Takeichi M (1992) E-cadherin expression in a particular subset of sensory neurons. Dev Biol 152:242-254.

Shimoyama Y, Tsujimoto G, Kitajima M, Natori M (2000) Identification of three human type-II classic cadherins and frequent heterophilic interac- 
tions between different subclasses of type-II classic cadherins. Biochem J 349:159-167.

Suzuki SC, Inoue T, Kimura Y, Tanaka T, Takeichi M (1997) Neuronal circuits are subdivided by differential expression of type-II classic cadherins in postnatal mouse brains. Mol Cell Neurosci 9:433-447.

Swandulla D, Carbone E, Schafer K, Lux HD (1987) Effect of menthol on two types of $\mathrm{Ca}$ currents in cultured sensory neurons of vertebrates. Pflugers Arch 409:52-59.

Takeichi M, Abe K (2005) Synaptic contact dynamics controlled by cadherin and catenins. Trends Cell Biol 15:216-221.

Teclemariam-Mesbah R, Wortel J, Romijn HJ, Buijs RM (1997) A simple silver-gold intensification procedure for double DAB labeling studies in electron microscopy. J Histochem Cytochem 45:619-621.

Togashi H, Abe K, Mizoguchi A, Takaoka K, Chisaka O, Takeichi M (2002) Cadherin regulates dendritic spine morphogenesis. Neuron 35:77-89.

Tominaga M, Caterina MJ (2004) Thermosensation and pain. J Neurobiol 61:3-12.

Tsuzuki K, Xing H, Ling J, Gu JG (2004) Menthol-induced $\mathrm{Ca}^{2+}$ release from presynaptic $\mathrm{Ca}^{2+}$ stores potentiates sensory synaptic transmission. J Neurosci 24:762-771.
Uchida N, Honjo Y, Johnson KR, Wheelock MJ, Takeichi M (1996) The catenin/cadherin adhesion system is localized in synaptic junctions bordering transmitter release zones. J Cell Biol 135:767-779.

Wang H, Woolf CJ (2005) Pain TRPs. Neuron 46:9-12.

Yagi T, Nada S, Watanabe N, Tamemoto H, Kohmura N, Ikawa Y, Aizawa S (1993) A novel negative selection for homologous recombinants using diphtheria toxin A fragment gene. Anal Biochem 214:77-86.

Yamagata M, Weiner JA, Sanes JR (2002) Sidekicks: synaptic adhesion molecules that promote lamina-specific connectivity in the retina. Cell 110:649-660.

Yang K, Kumamoto E, Furue H, Yoshimura M (1998) Capsaicin facilitates excitatory but not inhibitory synaptic transmission in substantia gelatinosa of the rat spinal cord. Neurosci Lett 255:135-138.

Yoshimura M, Nishi S (1993) Blind patch-clamp recordings from substantia gelatinosa neurons in adult rat spinal cord slices: pharmacological properties of synaptic currents. Neuroscience 53:519-526.

Zylka MJ, Rice FL, Anderson DJ (2005) Topographically distinct epidermal nociceptive circuits revealed by axonal tracers targeted to Mrgprd. Neuron 45:17-25. 